\title{
HUBUNGAN ANTARA KOMUNIKASI INTERPERSONAL SALES DENGAN PERILAKU KONSUMTIF
}

\author{
Oleh: \\ Rosyidah Umpu Malwa \\ Sekolah Tinggi Ilmu Psikologi Abdi Nusa \\ Jalan Veteran Palembang
}

\begin{abstract}
Honda Union Palembang customers are generally upper middle class customers who tend to have buying behavior based on their wishes. This customer tends to fulfill his needs a bit exaggerated (consumptive behavior). From this fulfillment customers tend to buy a car because of interest in the latest unit variants, purchased packages that are considered cheap, or because bored with old cars. This should be understood by Honda sales, where they should be able to understand the market situation, so it can attract interest from customers. Sales must be able to understand and convey Honda car information to customers well and effectively (interpersonal communication). So that the desired positive impact can occur ie the occurrence of sale and purchase transactions.

The population in this study is a customer of Honda Union who made a purchase in March 2017 which amounted to 50 people aged 19-55 years of male and female sex.

Data collection method or instrument used that is using likert scale method. Product Moment Pearson correlation analysis results. A correlation coefficient of 0.621 was obtained with a significance value of $0.000(p<0.05)$. The result of the closeness of the relationship is $38.56 \%$. It shows that there is a significant influence between interpersonal communication to consumptive behavior. While $61.44 \%$ is the influence of other factors.
\end{abstract}

Keywords: interpersonal communication, consumptive behavior, customer.

\begin{abstract}
ABSTRAK
Pelanggan Honda Union Palembang umumnya pelanggan kelas menengah keatas yang cendrung memiliki perilaku membeli yang berdasarkan keinginan saja. Pelanggan ini cendrung dalam pemenuhan kebutuhannya sedikit berlebihan (perilaku konsumtif). Dari pemenuhan ini pelanggan cendrung membeli mobil karena ketertarikan terhadap varian unit terbaru, paket pembelian yang dianggap murah, ataupun karena bosan dengan mobil lamanya. Hal inilah yang harus di pahami oleh sales Honda, dimana mereka harus dapat memahami situasi pasar, sehingga dapat menarik minat dari pelanggan. Sales harus dapat memahami dan menyampaikan informasi mobil Honda ke pelanggan dengan baik dan efektif (komunikasi interpersonal). Sehingga dampak positif yang diinginkan dapat terjadi yakni terjadinya transaksi jual beli.
\end{abstract}


Populasi dalam penelitian ini adalah pelanggan Honda Union yang melakukan pembelian pada bulan Maret 2017 yang berjumlah 50 orang yang berusia 19-55 tahun yang berjenis kelamin laki-laki dan perempuan.

Metode pengumpulan data atau instrument yang digunakan yakni menggunakan metode skala likert. hasil analisis korelasi Product Moment Pearson. Diperoleh koefisien korelasi sebesar 0,621dengan nilai signifikansi 0,000 ( $\mathrm{p}<0,05)$. hasil keeratan hubungan keduanya sebesar 38,56\%. Hal tersebut menunjukan bahwa adanya pengaruh yang siknifikan antara komunikasi interpersonal terhadap perilaku konsumtif. Sedangkan $61,44 \%$ merupakan pengaruh dari faktor lain.

\section{Kata kunci : komunikasi interpersonal, perilaku konsumtif, pelanggan.}

\section{PENDAHULUAN}

Pelanggan yang akan dibahas pada penelitian ini adalah pelanggan yang membeli karena berdasarkan keinginan bukan berdasarkan kebutuhan. Adanya perilaku pemenuhan kebutuhan yang terbilang cukup berlebihan bahkan memaksakan diri dari pelanggan, dimana pelanggan melakukan hal-hal yang terkadang merugikan dirinya sendiri secara materi dan tidak memperhitungkan untung dan rugi demi dapat memenuhi keinginan untuk mendapatkan mobil terbaru.

Selain itu karakteristik pemilik pelanggan merk Honda umumnya memiliki rasa loyalitas yang tinggi terhadap merk Honda itu sendiri, umumnya jika mereka telah memiliki mobil dengan merk Honda, mereka akan dengan sendirinya memilih untuk mobil kedua dan seterusnya juga dengan merk Honda. Maka dari itu pihak main dealer Honda selalu berusaha untuk menjalin silahturahmi dengan pelanggannya agar tidak kecewa dan berpindah menggunakan merk mobil kompetitor.

Komunikasi interpersonal yang baik merupakan sesuatu yang sangat penting dalam hal penyampai informasi dalam transaksi jual beli.Banyak hal yang di lakukan sales dalam menarik minat pelanggan dalam menjual mobil baru. Adanya penyampaian informasi yang berakhir pada pengertian, pemahaman, dan minat pada pelanggan. Dari hal inilah terlihat sales memiliki kemampuan komunikasi interpersonal yang baik.

Dari fenomena-fenomena tersebut diatas, bahwa kemampuan sales dalam berkomunikasi dapat di katakan baik sangat berkaitan erat dengan kemampuan sales dalam menguasai pengetahuan tentang produk-produk mobil Honda, cara sales dalam 
menarik minat pelanggan serta mengatasi keberatan yang di ajukan pelanggan, serta bagaimana cara sales dalam bersikap ketika bertemu dengan pelanggan.

Dari uraian diatas peneliti tertarik untuk melakukan penelitian pada pelanggan yang ada di PT. Honda Union Motor Palembang tentang Hubungan Antara Komunikasi Interpersonal Sales dengan Perilaku Konsumtif pada Pelanggan PT. Honda Union Motor Palembang.

Berdasarkan latar belakang di atas, maka identifikasian masalah yang dapat diambil sebagai berikut :

1. Apakah dampak dari komunikasi interpersonal dalam pembentukan perilaku konsumtif pelanggan?

2. Bagaimana cara melatih komunikasi interpersonal terhadap sales di PT. Honda Union Motor Palembang?

3. Bagaimana Hubungan Antara Komunikasi Interpersonal Sales dengan Perilaku Konsumtif pada Pelanggan PT. Honda Union Motor Palembang.?

\section{KERANGKA TEORITIS Perilaku Konsumtif}

Menurut Rasimin (dalam Lestari, 2006) menambahkan bahwa perilaku konsumtif merupakan kecenderungan untuk bertindak dengan keinginan untuk membeli dan menggunakan atau menghabiskan barang atau jasa yang sebenarnya kurang atau tidak diperlukan.

Berdasarkan uraian di atas dapat disimpulkan bahwa Perilaku Konsumtif adalah kecendrungan perilaku pelanggan PT. Honda Union Motor Palembang dalam pola hidupnya yang modern yang mempunyai kecendrungan bertindak dengan keinginan membeli mobil secara berlebihan meskipun dirinya tidak membutuhkan, hanya sekedar untuk menunjukan status sosial dan memperoleh kesenangan.

\section{Faktor-Faktor Prilaku Konsumtif}

Bila berbicara tentang perilaku konsumtif, maka tidak lepas dari masalah proses keputusan pembelian. Sigit (dalam Lestari, 2006) ada dua faktor yang mempengaruhi keputusan seseorang dalam melakukan pembelian. Faktor pertama adalah sikap orang lain dan faktor kedua adalah situasi-situasi yang tidak terduga. 


\section{Aspek-Aspek Perilaku Konsumtif}

Kemudian Rasimin (dalam Lestari, 2006) menambahkan aspek-aspek yang terdapat dalam perilaku konsumtif antara lain:

\section{a. Aspek Motif}

Meliputi dorongan-dorongan yang bersifat rasional maupun yang irasional, ikutikutan atau uji coba. Pada awalnya dorongan konsumen untuk melakukan tindakan pemilihan diantara berbagai jenis dan macam produk dipengaruhi oleh kualitas produk itu sendiri yang dianggap paling baik atau harganya cukup terjangkau. Namun kenyataannya sering kali pertimbangan tersebut bukan hanya sekedar kualitas dan faktor marketingnya, tetapi ada dorongan lain yang akan menimbulkan keputusan dalam membeli yang lebih bersifat psikologis, sehingga akan menimbulkan dasar pertimbangan yang irasional dan lebih bersifat emosional dalam pengertiannya, karena hasil produk tersebut dapat meningkatkan harga diri atau self estem serta dikagumi.

b. Aspek Kemutakhiran Mode Mencakup macam-macam barang atau jasa yang sedang popular dan digemari oleh orang banyak, sehingga orang cenderung beranggapan bahwa dirinya prestissius bila mengkonsumsi produk-produk dengan merek tertentu, produk tersebut dianggap fasionable.

c. Aspek Inferiority Complex

Berkaitan dengan masalah harga diri yang rendah, kurang percaya diri, gengsi. Konsumen yang tidak yakin pada dirinya sendiri, maka ia akan membeli produk dengan tujuan agar mendapatkan simbol status pribadi.

\section{Komunikasi Interpersonal Sales}

Menurut Devito (dalam Effendy, 2003) komunikasi Interpersonal adalah penyampaian pesan oleh satu orang dan penerimaan pesan oleh orang lain atau sekelompok kecil orang, dengan berbagai dampaknya dan dengan peluang untuk memberikan umpan balik segera.

Dari uraian di atas yang menjelaskan pengertian komunikasi interpersonal sales maka peneliti dapat menarik kesimpulan bahwa Komunikasi interpersonal adalah proses penyampaian pesan antara pelanggan PT. Honda Union Motor dengan sales PT. Honda Union Motor dalam bertukar informasi mengenai mobil, dengan berdampak terjadinya pembelian mobil.

\section{Faktor-Faktor Komunikasi Interpersonal}

Effendy (2001) mengatakan agar terjadi komunikasi interpersonal yang efektif, maka faktor-faktor komunikasi yang perlu diperhatikan sebagai berikut 
a. Komunikator

Seorang komunikator harus terpercaya (credible), agar mendapat kepercayaan dari komunikan. Komunikator akan mampu mengubah sikap, opini, dan perilaku komunikan melalui mekanisme daya tarik.

b. Pesan

Schramm (1971) dan Effendi (1993) menyebutkan bahwa agar pesan mendapat tanggapan baik dari komunikan hendaknya pesan harus dirancang dan disampaikan sedemikian rupa sehingga dapat menarik perhatian komunikan, harus menggunakan lambang-lambang tertuju kepada pengalaman bersama antara komunikator dan komunikan sehingga sama-sama mengerti, pesan harus membangkitkan kebutuhan pribadi komunikan dan menyarankan suatu jalan untuk memperoleh kebutuhan yang layak.

c. Saluran

Menurut pendapat Rogers (2003) bahwa saluran komunikan yang dapat dipergunakan dalam proses difusi inovasi adalah media massa dan media interpersonal.

d. Komunikan

bahwa komunikan akan menerima suatu pesan apabila berada dalam kondisi komunikan benar-benar mengerti apa yang dimaksud dari komunikator, pada saat dia mengambil keputusan, dia sadar bahwa keputusannya sesuai dengan tujuannya, pada saat mengambil keputusannya bersangkutan dengan kepentingan pribadinya, dan mampu menempatinya baik secara mental ataupun secara fisik.

\section{Aspek-Aspek Komunikasi Interpersonal}

Aspek-aspek komunikasi interpersonal oleh Devito (2009) yang meliputi

a. Keterbukaan (openness)

Pada hakekatnya setiap manusia suka berkomunikasi dengan manusia lain, karena itu tiap-tiap orang selalu berusaha agar mereka lebih dekat satu sama lainnya. Faktor kedekatan atau proximity bisa menyatukan dua orang yang erat. Kedekatan antar pribadi mengakibatkan seseorang bisa dan mampu menyatakan pendapatpendapatnya dengan bebas dan terbuka. Kebebasan dan keterbukaan akan memengaruhi berbagai variasi pesan baik verbal maupun nonverbal. Ini menunjukkan kualitas dari keterbukaan dari komunikasi antar pribadi yang mengandung dua aspek, yaitu aspek pertama keinginan untuk terbuka bagi setiap orang yang berinteraksi dengan orang lain. Hal ini tidak berarti harus menceritakan semua latar belakang kehidupan. Namun yang penting ada kemauan untuk membuka diri pada masalah-masalah umum. Dari sini orang lain akan mengetahui pendapat, pikiran dan gagasannya sehingga komunikasi akan mudah dilakukan, dan aspek keinginan untuk menanggapi secara jujur semua stimuli yang datang kepadanya. Dengan demikian komunikasi interpersonal dapat dikatakan efektif jika keterbukaan dalam berkomunikasi ini dilakukan. Aspek kedua dari keterbukaan menunjuk pada kemauan seseorang untuk memberikan tanggapan terhadap orang lain dengan jujur dan terus terang dan demikian pula sebaliknya.

b. Perilaku positif (positiviness)

Dalam komunikasi interpersonal kualitas ini paling sedikitnya terdapat tiga aspek perbedaan atau unsur, yaitu komunikasi interpersonal akan berhasil jika terdapat 
perhatian yang positif terhadap diri seseorang, komunikasi interpersonal akan terpelihara baik jika suatu perasaan positif terhadap orang lain itu dikomunikasikan, suatu perasaan positif dalam situasi umum amat bermanfaat untuk mengefektifkan kerjasama.

c. Empati (empathy)

Kemampuan memproyeksikan diri kepada peranan orang lain maupun mencoba merasakan dalam cara yang sama dengan perasaan orang lain. Dengan kerangka empati ini maka seseorang akan memahami posisinya dengan begitu tidak akan memberikan penilaian pada perilaku atau sikap orang lain sebagai perilaku atau sikap yang salah atau benar.

d. Perilaku suportif (suportiveness)

Komunikasi interpersonal akan efektif bila dalam diri seseorang ada perilaku suportif. Artinya seseorang dalam menghadapi suatu masalah tidak bersikap bertahan / defensif. Keterbukaan dan empati tidak dapat berlangsung dalam suasana yang tidak suportif. Gibb (Devito, 2009) menyebutkan tiga perilaku yang menimbulkan perilaku suportif, yakni deskriptif, spontanitas dan provisionalisme. Dalam perilaku deskriptif ditandai dengan perilaku evaluasi, strategi dan kepastian. Deskriptif artinya seseorang yang memiliki sifat ini lebih banyak meminta informasi atau deskripsi tentang suatu hal. Dalam suasana seperti ini biasanya orang tidak merasa dihina atau ditantang tetapi merasa dihargai. Sedangkan orang yang memiliki sifat evaluative cenderung menilai dan mengecam orang lain dengan menyebutkan kelemahan-kelemahan perilakunya. Spontanitas adalahindividu yang terbuka dan terus terang tentang apa yang dipikirkannya. Biasanya orang seperti itu akan ditanggapi dengan cara yang sama terbuka dan terus terang. Provisionalisme adalah individu yang memiliki sikap berpikir terbuka, ada kemauan untuk mendengar pandangan yang berbeda dan bersedia menerima pendapat orang lain bila pendapatnya keliru. Orang yang memiliki sifat ini tidak bertahan dengan pendapatnya sendiri sementara orang yang memiliki sifat kepastian merasa bahwa ia telah mengetahui segala sesuatunya dan merasa yakin bahwa pendapatnya yang paling benar.

e. Kesamaan (equality)

Kesamaan yaitu meliputi kesamaan dalam dua hal. Pertama kesamaan bidang pengalaman diantara para pelaku komunikasi. Artinya komunikasi antar pribadi umumnya akan lebih efektif bila para pelakunya mempunyai nilai, sikap, perilaku dan pengalaman yang sama. Namun hal ini tidak berarti bahwa ketidaksamaan tidaklah komunikatif. Komunikasi dengan individu yang tidak memiliki kesamaan tetap akan berjalan efektif apabila kedua belah pihak saling menyesuaikan diri. Kedua, kesamaan dalam percakapan diantara para pelaku komunikasi, maksudnya ada kesamaan dalam hal mengirim dan menerima pesan. Dalam setiap situasi seringkali terjadi ketidaksamaan. Tidak pernah ada dua orang yang benar-benar setara dalam segala hal. Terlepas dari ketidaksamaan ini komunikasi interpersonal akan lebih efektif kalau suasananya setara. Artinya harus ada pengakuan secara diam-diam bahwa kedua belah pihak sama-sama bernilai dan berharga. Dalam hubungan antar pribadi yang ditandai oleh kesamaan, ketidaksependapatan dan konflik lebih dilihat sebagai upaya untuk memahami perbedaan yang pasti ada, jika dibandingkan sebagai kesempatan untuk menjatuhkan pihak lain. Kesamaan tidak 
mengharuskan menerima dan menyetujui semua perilaku orang lain. Kesamaan berarti menerima pihak lain atau memberikan penghargaan yang positif tak bersyarat kepada pihak lain

\section{METODE PENELITIAN}

Populasi penelitian ini adalah seluruh pelanggan di PT. Honda Union Motor Palembang yang berjumlah 50 pelanggan. Teknik sampel peneliti menggunakan teknik sampel accidental.

Pengumpulan data dalam penelitian ini dilakukan dengan penyebaran skala psikologi. Skala-skala dalam penelitian ini menggunakan skala metode likert. Alternatif jawaban yang tersebar dalam bentuk favourable dan unfavourable

\section{Indikator Komunikasi Interpersonal:}

Keterbukaan (openness)

Perilaku positif (positiviness)

Empati (empathy)

Perilaku suportif (suportiveness)

Kesamaan (equality)

\section{Indikator Perilaku Konsumtif}

Aspek motif

Aspek kemutahiran mode

Aspek inferiority complex

\section{Uji Validitas}

Validitas yang digunakan dalam penelitian ini adalah validitas isi (content validity).Keaslian aitem dinyatakan secara empiris oleh suatu koefisien validitas tertentu. Koefisien validitas mempunyai makna jika bergerak dari 0,00 sampai dengan 0.01 dan batas minimum koefisien korelasi sudah dianggap memuaskan jika mencapai 0,3 (Arikunto, 2013). Teknik yang digunakan adalah Pearson Product Moment dari Karl Pearson dengan bantuan program computer stastistical packages for social sciences (SPSS) versi 16.0 for Windows.

\section{Uji Reliabilitas}

Uji reliabilitas pada penelitian ini menggunakan Alpha Cronbach, karena pembelahan tes tidak hanya terbatas pada aitem-aitem tes kedalam dua belahan saja, cara-cara pembelahan dapat diperluas pemakaiannya untuk membagi tes menjadi bebrapa belahan apabila diperlukan. 


\section{Teknik Analisis Data}

Untuk menganalisa data digunakan uji statistik kemudian untuk menguji hipotesis digunakan korelasi Product Moment, yang bertujuan untuk mengetahui Hubungan Antara Komunikasi Interpersonal Sales Dengan Perilaku Konsumtif Pada Pelanggan PT. Honda Union Motor Palembang. Sebelum menggunakan teknik korelasi Product Moment dilakukan uji prasyarat yaitu uji normalitas dan homogenitas sebaran data, jika terbukti sebaran data itu normal maka dapat digunakan uji statistik product moment dari Pearson, jika tidak normal digunakan korelasi Product Moment dari Spearman Rank Correlation atau kata jenjang.

\section{HASIL DAN PEMBAHASAN}

\section{a. Hasil Validitas Uji Coba Skala Perilaku Konsumtif}

Skala perilaku konsumtif terdiri 48 butir item. Setelah dilakukan uji validitas terhadap butir-butir item tersebut, diperoleh sebanyak 39 item yang valid, Koefesien validitas tersebut berkisar antara 0,308 sampai 0,557 dengan $r_{\text {hitung }}>r_{\text {tabel }}=0,279$. Item yang gugur berjumlah 9 item, yaitu 6, 18, 22, 24, 30, 32, 38, 40, 45. Dengan koefesien validitas berkisar antara -0,179 sampai 0,271 dengan $r_{\text {hitung }}<r_{\text {tabel }}=0,279$.

\section{b. Uji Reliabilitas Skala Perilaku Konsumtif}

Berdasarkan hasil pengelolahan data pada pengujian reliabilitas, diperoleh nilai alpha $=0,888$ yang artinya lebih mendekati angka 1,00, sehingga dapat disimpulkan bahwa skala yang digunakan memiliki tingkat keandalan dan memenuhi syarat untuk digunakan sebagai alat ukur penelitian.

\section{c. Hasil Validitas Uji Coba Skala Komunikasi Interpersonal}

Skala komunikasi interpersonal terdiri 50 butir item. Setelah dilakukan uji validitas terhadap butir-butir item tersebut, diperoleh sebanyak 40 item yang valid, Nilai koefesien validitas tersebut berkisar antara 0,302 sampai 0,561 dengan $r_{\text {hitung }}>r_{\text {tabel }}=0,279$. Item yang gugur berjumlah 10 item, yaitu 11, 17, 21, 30, 31, 34, 41, 45, 46, 48. Dengan koefesien validitas berkisar antara -0,067 sampai 0,249 dengan $r_{\text {hitung }}<r_{\text {tabel }}=0,279$. 


\section{d. Uji Reliabilitas Skala Komunikasi Interpersonal}

Berdasarkan hasil pengelolahan data pada pengujian reliabilitas, diperoleh nilai alpha $=0,884$ yang artinya lebih mendekati angka 1,00, sehingga dapat disimpulkan bahwa skala yang digunakan memiliki tingkat keandalan dan memenuhi syarat untuk digunakan sebagai alat ukur penelitian.

\section{Deskripsi Data Penelitian \\ a. Data Perilaku Konsumtif}

pada skala perilaku konsumtif diperoleh nilai rata-rata 119,02 dengan standar deviasi 13,187, nilai tengah 117,00 , nilai yang sering muncul 117, nilai terendah sebesar 71 dan nilai tertinggi sebesar 144 .

\section{b. Data komunikasi interpersonal}

Pada skala komunikasi Interpersonal diperoleh nilai rata-rata 116,84 dengan standar deviasi 13,370, nilai tengah 117,00 , nilai yang sering muncul 114 , nilai terendah sebesar 80 dan nilai tertinggi sebesar 159.

\section{Uji Persyaratan Analisa Data}

\section{a. Uji Normalitas}

Adapun hasil uji normalitas yang telah dilakukan terhadap variabel perilaku konsumtif dan komunikasi interpersonal adalah sebagai berikut:

a. Hasil uji normalitas variabel perilaku konsumtif diperoleh nilai K-SZ sebesar 1,002 dengan nilai $\mathrm{P}=0,268$

b. hasil uji normalitas variabel komunikasi interpersonal diperoleh nilai K-SZ sebesar 0,776 dengan nilai $\mathrm{P}=0,583$

\section{b. Uji Hipotesis}

Dari hasil analisis korelasi Product Moment Pearson. Diperoleh koefisien korelasi sebesar 0,617dengan nilai signifikansi 0,000 ( $\mathrm{p}<0,05)$ dengan demikian $\mathrm{H}_{0}$ ditolak maka $\mathrm{H}_{\mathrm{a}}$ diterima, artinya ada hubungan yang signifikanAntara Komunikasi Interpersonal Sales dengan Perilaku Konsumtif pada Pelanggan PT.Honda Union Motor Palembang. 
Bobot keeratan hubungan antara kedua variabel, didapatkan dengan rumus koefisien determinasi yaitu $\mathrm{KD}=\mathrm{r}^{2} \mathrm{x} 100 \%$. Jika koefisien korelasi diolah dengan menggunakan rumus tersebut, maka diperoleh hasil keeratan hubungan keduanya sebesar $38,07 \%$. Hal tersebut menunjukan bahwa adanya pengaruh yang siknifikan antara komunikasi interpersonal terhadap perilaku konsumtif. Sedangkan 61,93 \% merupakan pengaruh dari faktor lain.

Berdasarkan hasil penelitian dapat diketahui ada hubungan yang signifikan antara komunikasi interpersonalterhadap perilaku konsumtif pada pelanggan Honda Union Palembang. Hal tersebut terbukti dari interprestasi angka korelasi yang diterima terkatagorikan hasil yang sedang menurut (sugiyono, 2007). hasil tersebut dapat dilihat dari koefisien korelasi (xry), sebesar = 0,617dan tingkat signifikan 0,000 ( $\mathrm{p}<0,05)$, yang menandakan bahwa hubungan yang terjadi adalah signifikan, artinya Ha diterima Ho ditolak. Sehingga hipotesis Ha yang diajukan yakni ada hubungan antarakomunikasi interpersonalterhadap perilaku konsumtif pada pelanggan Honda Union Palembang. Koefisiensi determinasi yang didapatkan sebesar 38,07\%. Artinya kedua variabel memiliki keeratan hubungan sebesar 38,07\%, baik sumbangan komunikasi interpersonaldengan perilaku konsumtifpelanggan, maupun perilaku konsumtif terhadap komunikasi interpersonal pada pelanggan.

\section{SIMPULAN DAN SARAN}

\section{Simpulan}

Berdasarkan nilai data yang telah dilakukan diperoleh nilai koefisien kolerasi (rxy) atau r-hitung sebesar $=0,617$. $r$ - hitung $(0,617)>\mathrm{r}$-tabel $(0,297)$ dengan nilai signifikansi $r x y=$ $0,000<\alpha, 0,05$, artinya Ha diterima dan Ho ditolak, sehingga hipotesis Ha yang diajukan yakni ada hubungan antara komunikasi interpersonal terhadap perilaku konsumtif pada pelanggan Honda Union Palembang. Berdasarkan hasil tersebut menunjukan bahwa ada hubungan yang signifikan antara komunikasi interpersonal terhadap perilaku konsumtif pada pelanggan Honda Union Palembang. Hal ini menunjukan bahwa komunikasi interpersonalpada pelanggan Honda Union Palembang menyumbangkan nilai koefisiensi determinasi sebesar 38,07\%, terhadap perilaku konsumtif. Artinya kedua variabel memiliki keeratan hubungan sebesar 38,07\%. 


\section{Saran}

Berdasarkan hasil penelitian yang telah dilakukan, berikut ini disampaikan beberapa saran, antara lain : 1) Bagi pelanggan Honda Union Palembang: Untuk menanggulangi perilaku konsumtif pelanggan itu sendiri, pelanggan dapat menilai dengan baik mana sales yang dapat di jadikan referensi untuk berkonsultasi dengan sales yang hanya ingin cepat menjual mobil dan mencapai target. 2) Bagi sales: Sales sebaiknya tetap dapat menjaga kepercayaan dari pelanggan dengan cara bersikap sopan, mempersiapkan pengetahuan mobil Honda, berbahasa yang di mengerti pelanggan, menjalin kedekatan dengan bersikap ramah dan bersahabat dengan pelanggan. 3) Bagi perusahaan: Loyalitas pelanggan merupakan suatu hal penting bagi perusahaan, maka dari itu sebaiknya sales di berikan fasilitas untuk dapat mengembangkan kemampuan komunikasi interpersonalnya untuk menarik pelanggan baru maupun menjaga pelanggan lama. 4) Bagi Penelitian Selanjutnya: Bagi peneliti selanjutnya diharapkan dapat lebih mengembangkan penelitian yang sejenis ini maupun memiliki arah yang berbeda tentunya dengan responden yang berbeda dengan jumlah responden yang lebih banyak untuk mendapatkan hasil yang lebih baik lagi, sehingga dapat memberikan kontribusi yang bermanfaat bagi perkembangan ilmu pengetahuan khususnya di bidang psikologi.

\section{DAFTAR PUSTAKA}

Abdulhak, ishak. 1995. Metodologi Pembelajaran Pada Pendidikan Orang Dewasa; Cipta Intelektual, Bandung.

A Devito, Joseph. 2009. Komunikasi Antarmanusia. Tanggerang Selatan:Karisma Publishing Group.

Agus M. Hardjana. (2003). Komunikasi intrapersonal \& Komunikasi Interpersonal.Yogyakarta: Penerbit Kanisius.

Arikunto, S. (2013). Prosedur Penelitian: Suatu Pendekatan Praktik. Jakarta: Rineka Cipta.

Arni Muhammad. 2009. Komunikasi Organisasi. Jakarta: Bumi Aksara

Assuari, A. 1987. Manajemen Pemasaran. Jakarta: Rajawali.

Aw, Suranto. 2010. Komunikasi Interpersonal. Yogyakarta. Graha Ilmu. 
Azwar, S. 2012. Reliabilitas dan Validitas. Yogyakarta: Pustaka Pelajar

Azwar, S. (2015). Penyusunan Skala Psikologi Edisi 2. Yogyakarta: Pustaka Belajar.

Azwar, S. (2016). Penyusunan Skala Psikologi Edisi.Yogyakarta: Pustaka Belajar.

Bungin, Burhan. 2008.Sosiologi Komunikasi (Teori, Paradigma, dan DiscourseTeknologi Komunikasi di Masyarakat). Jakarta: Kencana Prenada Media Group.

Cangara, Hafied H, 2006, Pengantar Ilmu Komunikasi, PT. Raja Grafindo Persada, Jakarta.

Cangara, Hafied. 2007. Pengantar Ilmu Komunikasi. Jakarta: PT. Raja GrafindoPersada.

Dedy Mulyana, 2000. “Ilmu Komunikasi, Pengantar”. Bandung : Remaja Rosadakarya

Duncan, Tom, 2005, Principle of Advertising and IMC, International Edition, Edisi Kedua, New York; McGraw Hill.)

Fromm, E. 1995. Masyarakat yang Sehat (Terjemahan Sutrisno). Jakarta : Yayasan Obor Indonesia.

Kartodihardjo, S. 1995. Konsumerisme dan Perlindungan Konsumen. Akademika. No. 1. Tahun XIII. Surakarta : Muhammadiyah University Press.

Kotler, P. 1997. Manajemen Pemasaran : Analisis, Perencanaan, Implementasi, dan Kontrol. Edisi Revisi (terjemahan Teguh, $H$ dan Antonius, $R$ ). Jakarta : Prehalindo.

Lestari, S. 2006. Hubungan Antara Harga Diri dan Konformitas dengan Perilaku Konsumtif terhadap Produk Fashion pada Remaja Putri. Skripsi (Tidak diterbitkan). Surakarta. : Fakultas Psikologi UMS.

Nugraha, Hafis, M. 2015. Hubungan Antara Stress Kerja Terhadap Kinerja Pegawai UGD Di Rumah Sakit Umum Daerah Sekayu. Perpustakaan sekolah tinggi ilmu psikologi (STIPSI) Abdi Nusa Palembang.

Onong U. Effendy, 1993. Ilmu Komunikasi Teori dan Praktek, Bandung : PT Remaja Rosdakarya.

Onong U. Effendy, 2001. Ilmu Komunikasi Teori dan Praktek, Bandung : PT Remaja Rosdakarya.

Onong U. Effendy, 2003. Ilmu Komunikasi Teori dan Praktek, Bandung : PT Remaja Rosdakarya. 
Potter dan Perry. 1993. Buku Ajar Fundamental Keperawatan: Konsep, Proses, dan Praktik Vol. 1. Jakarta: EGC.

Robbins, Stephen P, 2003. Perilaku Organisasi, Jilid 2, PT. Indeks Kelompok Gramedia, Jakarta.

Setiaji, B. 1995. Konsumerisme. Akademika. No. 1. Tahun XIII. Surakarta Muhammadiyah University Press.

Sugiyono. 2007. MetodePenelitian Kuantitatif Kualitatif dan R\&D. Bandung: Alfabeta

Sugiyono. 2011. MetodePenelitian Kuantitatif Kualitatif dan R\&D. Bandung: Alfabeta

Sutisna. 2001. Pemasaran, Perilaku Konsumen, Komunikasi Pemasaran. Bandung: Remaja Rosadakarya.

Wiryanto. 2004. Pengantar Ilmu Komunikasi. Penerbit PT. Gramedia Widiasarana Indonesia. Jakarta.

http://digilib.unila.ac.id/282/10/BAB\%20II.pdf

http://eprints.ums.ac.id/16919/3/BAB II.pdf

https://library.binus.ac.id/eColls/eThesisdoc/Bab2/2012-1.pdf 